\title{
INFLUÊNCIA DO ÁCIDO ASCÓRBICO EM ANASTOMOSES E ALÇAS JEJUNAIS ÍNTEGRAS DE RATO
}

\author{
Andy PETROIANU*, Soraya Diniz e SOUZA**, \\ Silmar Grey MARTINS*** e Luiz Ronaldo ALBERTI****
}

\begin{abstract}
RESUMO - Racional - O efeito do ácido ascórbico sobre os processos cicatriciais anastomóticos apresenta resultados conflitantes na literatura. Objetivo - Comparar a resistência cicatricial de anastomoses e de segmentos íntegros jejunais de ratos submetidos a administração de vitamina $C$, em distintos periodos pós-operatórios. Método - Foram estudados 50 ratos Wistar, submetidos a secção e subseqüente anastomose término-terminal de segmento jejunal, a $10 \mathrm{~cm}$ da flexura duodenojejunal. Os animais foram divididos em dois grupos ( $n=25)$ : Grupo I - controle; Grupo II - administração de vitamina C oral, $100 \mathrm{mg} / \mathrm{kg}$. Avaliaram-se as pressões de ruptura anastomótica e do segmento íntegro jejunal nos $3^{\circ}$, $5^{\circ}$, $7^{\circ}, 21^{\circ}$ e $28^{\circ}$ dias pós-operatórios. Resultados - Os ratos que receberam vitamina C apresentaram uma pressão de ruptura anastomótica maior nos $5^{\circ}, 7^{\circ}$ e $28^{\circ}$ dias pós-operatórios. O mesmo ocorreu com as pressões de ruptura do segmento integro jejunal dos ratos. Conclusões - A vitamina C aumentou a resistência das anastomoses jejunais dos ratos, tanto no pós-operatório imediato, quanto no tardio. Além disso, a resistência final dos segmentos jejunais íntegros dos ratos submetidos a administração de vitamina C foi significativamente maior do que no Grupo Controle.
\end{abstract}

DESCRITORES - Ácido ascórbico. Cicatrização de feridas. Anastomose cirúrgica. Jejuno. Ratos.

\section{INTRODUÇÃO}

No processo cicatricial, sob a influência da hipoxia tissular e dos macrófagos, os fibroblastos sintetizam o colágeno, que na sua passagem para o espaço extracelular polimeriza-se. Durante a síntese do colágeno, a prolina é incorporada à cadeia polipeptídica inicial e sofre a ação da peptidilprolina-hidroxilase e do oxigênio molecular, para transformar-se em hidroxiprolina. O mesmo ocorre com a lisina. A polimerização do colágeno requer a remoção dos peptídios terminais e a condensação das lisinas ${ }^{(9,11,29)}$.
Segundo a literatura, o ácido ascórbico atua como doador de elétrons para o processo de hidroxilação da prolina, durante a síntese do colágeno, fato esse que leva a suspeitar da sua demanda aumentada nos processos de reparação tecidual $^{(3,13,21)}$.

Estudos recentes mostraram diversas funções do ácido ascórbico, além daquelas já descritas nos processos de cicatrização de feridas. Atuando como antioxidante, esse ácido é capaz de captar o oxigênio livre decorrente do metabolismo celular, impedindo sua ligação com radicais livres, fenômeno que causaria dano celular ${ }^{(2,3,8)}$. É provável que o ácido ascórbico

Departamento de Cirurgia, Faculdade de Medicina Universidade Federal de Minas Gerais - FM-UFMG, Belo Horizonte, MG.

* Professor Titular do Departamento de Cirurgia da FM-UFMG. Docente Livre da Faculdade de Medicina de Ribeirão Preto da Universidade de São Paulo. Docente Livre da Universidade Federal de São Paulo. Doutor em Fisiologia e Farmacologia. Pesquisador IA do CNPq.

** Médica.

$* * * \quad$ Médico Residente.

**** Acadêmico de Medicina da FM-UFMG.

Endereço para correspondência: Dr. Andy Petroianu - Av. Afonso Pena, 1626, apto. 1901 - 30130-005, Belo Horizonte, MG. 
também esteja envolvido na manutenção da integridade intracelular com presença da integridade capilar, nas respostas imunológicas, reações alérgicas e aumento da absorção de ferro não-hémico ${ }^{(4,24)}$.

De acordo com estudos recentes, o intestino circunvizinho que participa da reação à lesão de uma anastomose jejunal perde grande parte de seu colágeno por lise, reduzindo assim a sua resistência ${ }^{(7,9)}$. Esses dados sugerem um importante papel da vitamina $\mathrm{C}$ sobre o processo de cicatrização. Todavia, a sua administração suplementar com o intuito de melhorar os processos cicatriciais é ainda debatido.

Dentro de uma linha de pesquisa ${ }^{(1,2,19)}$, o objetivo do presente trabalho foi avaliar a influência do ácido ascórbico sobre a tensão anastomótica e do segmento íntegro jejunal de ratos, em distintos períodos pós-operatórios.

\section{MATERIAL E MÉTODOS}

Foram estudados 50 ratos machos albinos da raça Wistar, pesando entre 250 e 400 gramas.

Sob anestesia inalatória com éter sulfúrico, todos os animais foram submetidos a laparotomia mediana ( $3 \mathrm{~cm}$ de extensão). Identificado o segmento jejunal a $10 \mathrm{~cm}$ da flexura duodenojejunal, foi realizada sua secção. Os cotos jejunais foram anastomosados término-terminal com pontos separados de categute 4-0. A parede abdominal foi fechada em dois planos com fio de polipropileno 3-0. Os ratos recuperaram-se espontaneamente da anestesia.

Os animais operados foram divididos aleatoriamente em dois grupos $(\mathrm{n}=25)$ :

- Grupo I , controle, animais submetidos apenas a cirurgia;

- Grupo II, administração oral de vitamina C na dose de $100 \mathrm{mg} /$ $\mathrm{kg} / \mathrm{dia}$, durante todo o período de acompanhamento pós-operatório.

Os animais foram avaliados diariamente. A vitamina $\mathrm{C}$ foi acrescentada à água oferecida a eles, de acordo com resultado do projeto piloto que determinou a quantidade média de água que os ratos ingeriam por dia $(80 \mathrm{~mL})$. Os animais receberam água pura (Grupo I) ou acrescida a vitamina $\mathrm{C}$ (Grupo II) e ração para ratos à vontade.

Cada grupo de animais foi subdividido em cinco subgrupos $(\mathrm{n}=$ 5) para estudo no $3^{\circ}, 5^{\circ}, 7^{\circ}, 21^{\circ}$ e $28^{\circ}$ dias pós-operatórios. A morte dos animais foi induzida com dose inalatória letal de éter.

Após desfazerem-se as aderências abdominais, com cuidado, foram retirados dois segmentos jejunais, medindo $10 \mathrm{~cm}$ cada um. $O$ primeiro segmento inseria em sua parte média a anastomose. O segundo segmento era constituído pelo jejuno imediatamente distal ao primeiro segmento.

Avaliaram-se as pressões de ruptura de ambos os segmentos por meio de um tensiômetro de mercúrio de três vias. A parte distal dos segmentos foi amarrada com fio de seda 2-0. Em sua parte proximal foi introduzida uma cânula de $1 \mathrm{~cm}$, conectada a um equipo de três vias que constituía o tensiômetro. As outras duas vias foram ligadas: a primeira a uma bomba de infusão com fluxo de ar controlável, e a segunda a uma coluna de mercúrio de $100 \mathrm{~cm}$ (Figura 1). O fluxo de ar foi calibrado para 150 bolhas por minuto, borbulhando a cânula em uma cuba com água. O segmento intestinal foi mergulhado $1 \mathrm{~cm}$ nessa cuba. Através da cânula introduzida no segmento jejunal, infundiu-se ar até a sua ruptura ser percebida pela saída de bolhas na água. Nesse momento, registrou-se o nível pressórico da coluna de mercúrio em centímetros.

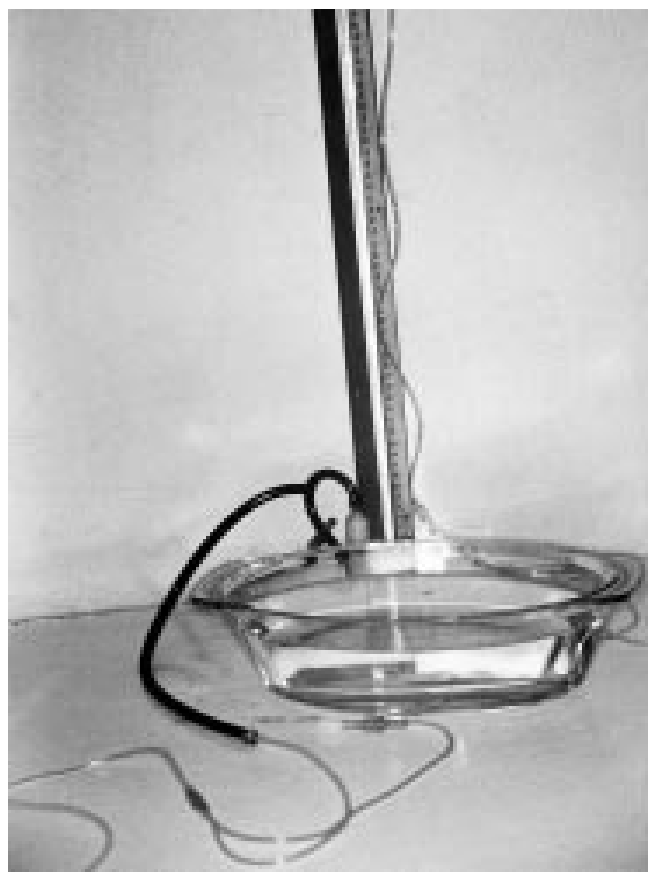

FIGURA 1 - Tensiômetro de três vias para medição da pressão de ruptura entérica e anastomótica

Os resultados foram comparados por meio dos testes $t$ Student e do qui-quadrado. As diferenças foram consideradas significativas para valores maiores aos correspondentes a $P<0,05$.

\section{RESULTADOS}

Os animais evoluíram satisfatoriamente. O retorno do trânsito digestório foi confirmado desde o primeiro dia pós-operatório, pela presença de fezes nas gaiolas. Nenhuma deiscência anastomótica foi observada.

A Tabela 1 mostra os valores pressóricos medianos de ruptura anastomótica em diferentes períodos pós-operatórios. Observa-se que o Grupo II apresentou valores pressóricos maiores nos $5^{\circ}, 7^{\circ} \mathrm{e}$ $28^{\circ}$ dias pós-operatórios. 
A análise de resistência no $3^{\circ}$ dia mostrou uma pressão igual a zero, para ambos os grupos. A diferença mais significativa foi para análise no $28^{\circ}$ dia pós-operatório, quando os ratos submetidos a administração de vitamina $C$ apresentaram tensão significativamente maior do que os do Grupo Controle. A resistência após 28 dias foi maior do que a encontrada nos períodos anteriores, para ambos os grupos.
A Tabela 1 mostra os valores pressóricos medianos de ruptura do segmento íntegro jejunal. Observa-se que as pressões do Grupo II foram maiores do que as do Grupo I, apesar de a diferença ser significativa apenas no $28^{\circ}$ dia pós-operatório. Após o $7^{\circ}$ dia não houve diferenças entre as resistências da anastomose e do segmento íntegro.

TABELA 1 - Pressão mediana (cm Hg) de ruptura da anastomose e do segmento íntegro jejunal

\begin{tabular}{|c|c|c|c|c|}
\hline \multirow{3}{*}{ Dias pós-operatórios } & \multicolumn{4}{|c|}{ GRUPOS } \\
\hline & \multicolumn{2}{|c|}{ I } & \multicolumn{2}{|c|}{ II } \\
\hline & Segmento íntegro & Anastomose & Segmento íntegro & Anastomose \\
\hline $3^{\circ}$ & 23,1 & 0 & 24,2 & 0 \\
\hline $5^{\circ}$ & 24,4 & $14,0^{*}$ & 27,3 & $18,9 *$ \\
\hline $7^{\circ}$ & 23,8 & 11,2 & 28,5 & 23,0 \\
\hline $21^{\circ}$ & 22,8 & 24,0 & 21,0 & 18,4 \\
\hline $28^{\circ}$ & $24,5^{*}$ & $33,6^{*}$ & $43,5^{*}+$ & $>45,0 *$ \\
\hline
\end{tabular}

Grupo I: controle

Grupo II: ácido ascórbico oral

* Diferente do outro grupo no mesmo dia pós-operatório $(P<0,05)$

+ Diferente das pressões encontradas nos demais períodos pós-operatórios

\section{DISCUSSÃO}

Fatores que afetam a cicatrização anastomótica vêm sendo pesquisados continuamente ${ }^{(1,2,7,15,18,19)}$. Entretanto, resultados de estudos experimentais que investigam a cicatrização em anastomoses intestinais, apresentam resultados conflitantes ${ }^{(1,2,19)}$. Embora existam estudos com corticosteróides e outras substâncias para avaliar sua influência em fenômenos cicatriciais ${ }^{(1,2,8,14,19,23)}$, pouco se pesquisou sobre o ácido ascórbico.

No presente trabalho, a dose de ácido ascórbico foi escolhida com base em trabalhos anteriores, que verificaram serem essas as concentrações mínimas capazes de afetar a cicatrização de feridas e passíveis de serem usadas em seres humanos, sem levar a efeitos tóxicos e lesivos quando administradas ${ }^{(26,27,28)}$

$\mathrm{O}$ uso do fármaco foi iniciado três dias antes do ato cirúrgico e estendeu-se até o dia em que os animais foram mortos ${ }^{(1)}$. Tal conduta seguiu orientações da literatura ${ }^{(28)}$.

Deiscência em anastomoses intestinais é complicação freqüente, sendo o colágeno de fundamental importância na manutenção de tensão na parede intestinal ${ }^{(7,10,25)}$. Investigações em anastomoses entéricas em vários animais mostraram mudanças maciças nas concentrações de colágeno, ocorrendo principalmente na primeira semana pósoperatória. Os resultados obtidos no presente estudo mostram aumento marcante da tensão cicatricial tanto no pós-operatório imediato, quanto no tardio, após ingestão de vitamina C.
Outro fator de destaque, é a influência negativa de microorganismos capazes de produzir enzimas colagenolíticas, que levariam a um desequilíbrio entre a síntese e a degradação de colágeno ${ }^{(18,20)}$. Isto sugere que, além da técnica cirúrgica e dos cuidados perioperatórios, a administração suplementar de vitamina $C$ possa ser benéfica no sentido de restabelecer o equilíbrio metabólico. Essa hipótese poderia contribuir para explicar em parte, os valores de tensão maiores encontrados nos grupos em que se administrou a vitamina $\mathrm{C}$.

No acompanhamento de 7 dias, todos os grupos apresentaram tensão cicatricial inferior à registrada no período de 21 dias. No início, a tensão cicatricial ainda é muito tênue, o que dificulta a análise do efeito do ácido ascórbico. Mesmo assim, observou-se que nos grupos tratados com a vitamina $\mathrm{C}$, a tensão foi maior em relação ao Grupo Controle. Entretanto, nossos dados não permitem explicar a fisiopatologia desses achados.

Segundo CHOWCAT et al. ${ }^{(6)}$, colagenase é sintetizada sob demanda e controlada por um inibidor tecidual de metaloproteinase. A suplementação de vitamina $\mathrm{C}$ mesmo que não tenha influência sobre essas enzimas, oferece aporte maior de substrato, que poderia ser responsável por reações químicas indutoras de síntese de colágeno ${ }^{(2,3,4,5,12,14,22)}$.

A transposição dos achados experimentais para a clínica deve ser cautelosa $^{(26)}$. Apesar de alguns trabalhos evidenciarem efeito benéfico da vitamina $C$, outros mostram que mecanismos inflamatórios (células e mediadores químicos) são os responsáveis pela regulação da síntese de colágeno ${ }^{(6,16,17)}$. 
Os resultados do presente trabalho sugerem um efeito positivo da vitamina $\mathrm{C}$, tanto nas fases iniciais, quanto nas tardias dos processos cicatriciais. Levando-se em conta que a maior parte das complicações (deiscências, fístulas) ocorrem no período pós-operatório imediato, julgamos pertinente supor que a administração de vitamina $C$ possa ser benéfica, mesmo na clínica, quando se trata de doenças crônicas ou degenerativas.

Outro aspecto que merece consideração é o fato de a administração de vitamina $C$ elevar a tensão de ruptura tardia do segmento jejunal íntegro significativamente maior do que a do Grupo Controle. Neste trabalho, não encontramos subsídio histológico que auxiliasse na explicação desse resultado. Portanto, essa resistência também requer maiores estudos para ser compreendida.

\section{CONCLUSÃO}

Com base nos dados do presente trabalho, a vitamina $\mathrm{C}$ contribuiu para aumentar a resistência das anastomoses jejunais e do segmento jejunal íntegro de rato, tanto no período pós-operatório imediato, quanto no tardio.

\section{AGRADECIMENTOS}

Os autores agradecem ao Conselho Nacional de Desenvolvimento Científico e Tecnológico (CNPq) e Fundação de Amparo à Pesquisa de Minas Gerais (FAPEMIG) pelos auxílios financeiros que permitiram a realização deste trabalho.

Petroianu A, Souza SD e, Martins SG, Alberti LR. Influence of ascorbic acid on anastomotic and jejunal resistance in rat. Arq Gastroenterol $2001 ; 38(1): 48-52$.

ABSTRACT - Backgroud - The effects of vitamin C on anastomotic healing process are controversial. Objective - To compare the jejunal anastomotic tension and in the upright segment in different postoperative periods. Method - Fifty male rats weighing 250 to 400 grams were submitted to laparotomy. The jejunum was transversally cut $10 \mathrm{~cm}$ from the duodenojejunal flexure, and subsequently anastomosed. The rats were divided into two groups $(\mathrm{n}=25)$. Group I - control, Group II - oral administration of vitamin C (100 mg/kg). The anastomotic and the upright segment resistance was determined by using bursting pressure test on the $3^{\text {rd }}, 5^{\text {th }}, 7^{\text {th }}, 21^{\text {st }}$ and $28^{\text {th }}$ postoperative days. Results - The rats submitted to oral administration of ascorbic acid show higher bursting pressure on the $5^{\text {th }}$, $7^{\text {th }}$ and $28^{\text {th }}$ postoperative days. The bursting resistances of the upright segment was higher on the rats submitted to vitamin $C$ ingestion. Conclusions - Vitamin C enhances the anastomotic and jejunal resistances. Moreover, the final resistance on the upright jejunal segment was significant higher than in the control group.

HEADINGS - Ascorbic acid. Wound healing. Anastomosis, surgical, Jejunum. Rats.

\section{REFERÊNCIAS BIBLIOGRÁFICAS}

1. Arantes VN, Okawa RY, Silva AA, Barbosa AA, Petroianu A. Efeito da metilprednisolona sobre a tensão anastomótica jejunal. Arq Gastroenterol 1994;31:97-101.

2. Arantes VA, Okawa RY, Pereyra WJF, Barbosa AJA, Petroianu A. Influência da icterícia obstrutiva na cicatrização da pele e de anastomose jejunal em ratos. Rev Col Bras Cir 1999;26:269-73.

3. Barbul A. Role of T-cell dependent immune system in wound healing. Biological and clinical implications. A R Liss 1988:161-75.

4. Barbul A. Immune aspects of wound repair. Clin Plast Surg 1990;17:433-42.

5. Carrico TJ, Mehrhofal AI Jr, Cohen IK. Biology of wound healing. Surg Clin North Am 1984;64:721-33, 1984

6. Chowcat NL, Savage FJ, Hembry RM, Boulos PB. Role of collagenase in colonic anastomoses: a reappraisal. Br J Surg 1988;75:330-3.

7. Cronin K, Jackson DS, Dumphy JE. Changing bursting strength and collagen content of the healing colon. Surg Gynecol Obstet 1068;126:747-53.

8. Del-Rio JV, Beck DE, Opelka FG. Chronic perioperative steroids and colonic anastomotic healing in rats. J Surg Res 1996;66:138-42.

9. Ehrlich HP. Wound clousure: evidences of cooperation between fobroblasts and collagenous matrix in scar contractor. Eye 1998;2:149-50.

10. Furst MB, Stromber BV, Blatchfford GJ, Christensen MA, Thorson AG. Colonic anastomoses. Dis Colon Rectum 1994;37:12-5.

11. Goffi FS. Ferimentos das partes moles e cicatrização. In: Goffi FS. Bases anatômicas, fisiopatológicas e técnicas da cirurgia. 4.ed. São Paulo: Atheneu; 1997. p.126-32.
12. Hesp WLEM, Hendriks T, Lubbens EC, de Boer HHM. Wound healing in the intestinal wall. Dis Colon Rectum 1984;27:99-104.

13. Hussain MZ, Ghani QP, Hunt TK. Inhibition of prolyl hydroxylase by poly (ADP-ribose) and phosphoribosyl-AMP. Possible role of ADP-ribosylation in intracellular prolyl hydroxylase regulation. J Biol Chem 1989;264:7850-5.

14. Irvin TT. Effects of malnutrition and hyperalimentation on wound healing. Surg Gynecol Obstet 1978; 146:33.

15. Jibborn H, Ahonen J, Zederfeldt B. Healing of experimental colonic anastomosis. Bursting strength of the colon after left colon resection and anastomosis. Am J Surg 1978;136:587-94.

16. King CG. Relation of ascorbic acid to other vitamins. Bibl Nutr Dieta 1070;15:80-4.

17. Lacroix B, Didier E, Grenier JF. Role of panthotenic and ascorbic acidon wound healing processes: in vitro study on fibroblasts. Int J Vitam Nutr Res 1988;58:407-13.

18. Mastboom WJB, Hendrikas T, De Boer HHM. Collagen changes around intestinal anastomoses in germ-free rats. Br J Surg 1989;76:797-801.

19. Melo MAB, Almeida LM, Barbosa AJA, Petroianu A. Cicatrização de anastomose colônica em ratos submetidos a diferentes preparos colônicos. Rev Bras Coloproctol 1996;16:19-22.

20. Peter Koffsky B. Bacterial collagenase. In: Cunninghan LW, Frederiksen DW, editors. Methods in enzymology. New York: Academic Press; 1982. p.453-71.

21. Rang HP, Dale NM. Hormônios locais, inflamação e alergia. In: Rang HP, Dale NM, editores. Farmacologia. 2.ed. Rio de Janeiro: Guanabara Koogan; 1993. p.152-72.

22. Ringsdorf WMJ. Vitamin C and human wound healing. Oral Surg 1982;53:231-6. 
Petroianu A, Souza SD e, Martins SG, Alberti LR. Influência do ácido ascórbico em anastomoses e alças jejunais íntegras de rato

23. Robinson MC. Disturbances of wound healing. Ann Emerg Med 1988;17:1274-8.

24. Taylor TV, Rimmer S, Day B, Butccher J, Dymock IW. Ascorbic acid supplementation in the treatment of pressure sorees. Lancet 1974;2:544-6.

25. Trott A. Mechanisms of surface soft tissue trauma. Ann Emerg Med 1988;17:1279-83.

26. Vaxman F. Improvement in the healing of colonic anastomoses by vitamin B-5 and C supplements. Ann Chir 1990;44:512-20.

27. Vaxman F. Effect of pantothenic acid and ascorbic acid supplementation on human skin wound healing process. Eur Surg Res 1995;3:158-66.
28. Vaxman F. Can the wound healing process be improved by vitamin supplementation? Eur Surg Res 1996;28:306-14.

29. Way L. Cicatrização de feridas. In: Way L. Cirurgia: diagnóstico e tratamento. 9.ed. Rio de Janeiro: Guanabara Koogan; 1991. p.67-75.

Recebido em 25/5/2000. Aprovado em 17/8/2000. 